\title{
Field Survey and Estimation of Residual Toxicity of Insecticides Used in Mulberry Growing Area of Karnataka, India
}

\author{
T. Sunil Kumar*, Ramakrishna Naika, G. Ashwini and K. Anitha \\ Department of Sericulture, University of Agricultural Sciences, Gandhi KrishiVignan \\ Kendra (GKVK), Bengaluru-560065, Karnataka, India \\ *Corresponding author
}

\section{A B S T R A C T}

Keywords

Application,

Insecticides,

Residue, Silkworm, Mulberry.

\section{Article Info}

Accepted:

28 October 2017

Available Online:

10 December 2017
The studies carried out on field survey and estimation of residual toxicity of insecticides used in mulberry growing area of karnataka. The field survey among 120 farmers in villages of Ramanagara, Chikkaballapur and Kolar districts revealed that the maximum toxicity of pesticides was due to the drift effect ( 66 farmers) followed by direct effect (38 farmers) and about 16 farmers were without any pesticide problem. Among 120 farmers 39 farmers preferred Chlorantrntraniliprole followed by Flubendamide (25 farmers), Dichlorvos (16 farmers), Imidacloprid (12 farmers), Carbaryl (6 farmers), Dimethoate (3 farmers) and Chlorpyrifos (3 farmers). The widely used pesticide is subjected for residue analysis. Results of analysis of fifteen mulberry leaf and soil samples collected from different sericulture farmer fields in Kolar and Chikkaballapura district for insecticides residue. Showed that out of fifteen samples, six samples had detectable level of pesticides residue highest residual toxicity effect is due to Chlorantraniliprole insecticide is came to know from this research.

\section{Introduction}

The fabulous sericulture industry was originated in China at Chin-Tong Province during 3000 B.C. Silk, the "Queen of textiles", unchallenged so far by other fibres, is a nature's gift for mankind. Silk with its fineness, evenness, durability and luster had fascinated the woman folk. Sericulture is an important and highly remunerative agro-based industry. Mulberry is infested by several pests. These pests affect the growth of mulberry and cause considerable damage to the plant and loss in leaf yield. The insecticides applied for the control of mulberry pests in turn have a greater impact on silkworm. Chandrashekharan (2007)
Apart from this, mulberry is grown adjacent to the commercial crops. The plant protection measures taken on the commercial crops may drift to the mulberry garden and thus, affect the growth, development, fecundity and survival of Bombyx mori L. (Roxelle et al., 2013).

\section{Materials and Methods}

Personal interview method was for collection of data. The field survey was conducted in Mailandahalli, Jodi hosalli villages of Chikkaballapura district. Mullahalli, Guttahalli of Kolara District, Shivanasandra, 
Shingrigowdarapaalya, Udavegere, Nallahalii Doddamuddigere, Chunchikaaloni of Ramanagara district to record the types of insecticides used by the farmers (120) in mulberry growing areas with the help of pre structured schedule. Similarly, the practices followed by the farmers to overcome the inseticide toxicity in mulberry growing areas were documented. The most widely used insecticides to control pest infestation in inter crop is selected for further experimentation. The field survey conducted during August 2016.

Pesticides residue level in soil and mulberry leaves was quantitatively measured by using Quech ERS Multi-residue method developed by Anastassiades and Lehotay in 2003. For estimation of pesticide residue level, $10 \mathrm{gm}$ soil was taken in centrifuge tube, 4 drops of diluted ammonia was added and $15 \mathrm{ml}$ of acetonitrite, $2-3 \mathrm{gm}$ of NACL, $1.2 \mathrm{gm}$ of $\mathrm{MgSO}_{4}$ were added and centrifuged at 3000 rpm for $30 \mathrm{~min}$.

Eight $\mathrm{ml}$ of supernatant was taken in another centrifuge tube, to which $0.2 \mathrm{gm}$ PSA and $1.2 \mathrm{gm} \mathrm{MgSO}_{4}$ were added centrifuged for 30 $\mathrm{min}$ at $4000 \mathrm{rpm}$ and $2 \mathrm{ml}$ of supernatant was taken for injection into $\mathrm{GC/LC}($ Gass/liquid chromatography). The same procedure was followed for estimation of pesticide residues in leaf, but here fresh leaves were dried to make $15 \mathrm{gm}$ of powdered mulberry leaves.

\section{Results and Discussion}

The field survey conducted among 120 farmers in villages of Ramanagara, Chikkaballapur and Kolar districts revealed that the maximum toxicity of pesticides was due to the drift effect (66 farmers) followed by direct effect (38 farmers) and about 16 farmers were without any pesticide problem (Table 1). It was clear from the survey that Chlorantraniliprole,

Flubendiamide,
Imidacloprid, Dichlorovas. Insecticides were most commonly used in mulberry growing areas to manage the pests of tomato, mango, rose, pigeon pea and other crops. The drifting of the insecticide on to mulberry leaves has resulted in poor cocoon production. Similar observation was made by (Roxelle et al., 2013) with respect to the insecticide coragen. Silkworms constructed thin shelled cocoons and matured worms vomited yellow coloured liquid, which was due to insecticide contaminated mulberry leaves fed to the silkworms. The toxicity hazardous was mainly due to lack of knowledge about the use of insecticides and injudicious application of pesticides. Similar reports were made by earlier workers (Jyothi et al., 2013).

The survey revealed that thefarmers in the Kolar and Chikkaballapura Districts are losing cocoon crops, even after the adoption of recommended technologies for silkworm rearing, mulberry and silkworm pests and diseases management. In most of these cases, crop loss was not because of silkworm diseases, but due to toxicity or poisoning Avramova et al., (2012). The study revealed that chlorantraniliprole insecticide was most commonly used in these areas to manage the pests of tomato was reported by Kumutha et al., (2013).

Similarly farmers of these districts were extensively using the pesticides viz., dichlorvos ( $2 \mathrm{ml} /$ litre), imidacloprid (0.5$1 \mathrm{ml} / \mathrm{litre})$, chlorantraniliprole $(0.2-0.5$ $\mathrm{ml} /$ litre), Flubendiamide (0.5-1 $\mathrm{ml} / \mathrm{litre})$, Chlorpyrifos (1-3 $\mathrm{ml} /$ litre) above the recommended dosage to control pests and diseases of tomato, mango and other crops. Among them about 39 farmers preferred Chlorantrntraniliprole followed by Flubendamide (25 farmers), Dichlorvos (16 farmers), Imidacloprid (12 farmers), Carbaryl (6 farmers), Dimethoate (3 farmers) and Chlorpyrifos (3 farmers) (Table 2). 
Table.1 Status of insecticide toxicity in mulberry growing area of Kolar, Chikkabalapur and Ramanagara Districts

\begin{tabular}{|c|c|c|c|c|c|}
\hline \multirow{2}{*}{ Districts/Taluk } & \multirow{2}{*}{ Villages } & \multicolumn{2}{|c|}{$\begin{array}{l}\text { No. of farmers with } \\
\text { pesticide toxicity }\end{array}$} & \multirow{2}{*}{$\begin{array}{l}\text { No. of } \\
\text { farmers } \\
\text { free } \\
\text { from } \\
\text { toxicity }\end{array}$} & \multirow{2}{*}{ Total } \\
\hline & & Direct & Drift & & \\
\hline \multicolumn{6}{|l|}{ Raamanagara District } \\
\hline \multirow{5}{*}{ (MaagadiTaluk) } & Shivanasandra & 3 & 5 & 2 & 10 \\
\hline & Shingrigowdarapaalya & 2 & 4 & 0 & 6 \\
\hline & Togachagere & 5 & 2 & 3 & 10 \\
\hline & Udavegere & 3 & 7 & 3 & 13 \\
\hline & Nallahalii & 4 & 6 & 0 & 10 \\
\hline \multicolumn{6}{|l|}{ (RaamanagaraTaluk) } \\
\hline & Doddamuddigere & 5 & 6 & 2 & 13 \\
\hline & Chunchikaaloni & 3 & 5 & 0 & 8 \\
\hline \multicolumn{6}{|l|}{ Kolar District } \\
\hline \multirow{3}{*}{ (Kolar Taluk) } & Mullahalli & 3 & 5 & 1 & 9 \\
\hline & Arehalli & 3 & 5 & 0 & 8 \\
\hline & Guttahalli & 4 & 6 & 3 & 13 \\
\hline \multicolumn{6}{|c|}{ Chikkaballapura District } \\
\hline \multirow{3}{*}{ (Chintamani Taluk) } & Mailandahalli & 1 & 9 & 0 & 10 \\
\hline & Jodi hosalli & 2 & 6 & 2 & 10 \\
\hline & & 38 & 66 & 16 & $\begin{array}{l}\text { Grandtotal } \\
=120\end{array}$ \\
\hline
\end{tabular}

Table.2 Insecticide usage in mulberry growing areas in Ramanagara, Kolar and Chikkaballapura Districts

\begin{tabular}{|l|l|l|l|l|}
\hline Insecticides used & $\begin{array}{c}\text { Recommended } \\
\text { Dosage } \\
\text { (ml/liter) }\end{array}$ & $\begin{array}{c}\text { Used dosage to } \\
\text { control pest } \\
\text { (ml/liter) }\end{array}$ & \multicolumn{1}{|c|}{ Crop } & $\begin{array}{c}\text { No of } \\
\text { farmers }\end{array}$ \\
\hline Dichlorvos & $0.5 \mathrm{ml} /$ lit & $1-2 \mathrm{ml} /$ lit & Mulberry. & 16 \\
\hline Imidacloprid & $0.5 \mathrm{ml} /$ lit & $0.5-1 \mathrm{ml} /$ lit & Mulberry, Rose. & 12 \\
\hline Chlorantraniliprole & $0.03 \mathrm{ml} /$ lit & $0.2-0.5 \mathrm{ml} /$ lit & Mango, tomato. & 39 \\
\hline Malathion & $2 \mathrm{ml} /$ lit & $2-4 \mathrm{ml} /$ lit & Mango, Vegetables. & 6 \\
\hline Flubendiamide & $0.05 \mathrm{ml} /$ lit & $0.5-1 \mathrm{ml} /$ lit & $\begin{array}{l}\text { Pigeonpea, } \\
\text { Tomato. }\end{array}$ & 25 \\
\hline Dimethoate & $2 \mathrm{ml} /$ lit & $2 \mathrm{ml} /$ lit & Cotton. & 3 \\
\hline Chlorpyrifose & $2 \mathrm{ml} /$ lit & $4-5 \mathrm{ml} /$ lit & Paddy. & 3 \\
\hline & & & & Total = 104 \\
\hline
\end{tabular}


Table.3 Pesticide residue in soil samples collected from mulberry fields in Chikkaballapura and Kolar Districts

\begin{tabular}{|c|c|c|c|c|}
\hline $\begin{array}{c}\text { Sample } \\
\text { code }\end{array}$ & Name and village & Detected insecticide & $\begin{array}{c}\text { Level of } \\
\text { pesticide } \\
\text { residue (ppm) }\end{array}$ & $\begin{array}{c}\text { FAO/WHO } \\
\text { Recommended } \\
\text { MRL (ppm) }\end{array}$ \\
\hline F1 K & Bhairegowda, Mallandahally & PD.DDE & 2.68 & 3.5 \\
\hline F2 K & Vishwanath, Chikkakalahalli & Metalaxyl & 0.19 & 0.05 \\
\hline F3 K & Gouramma, Mullahalli & ND & ND & ND \\
\hline F4 K & Anjinappa, Guttahalli & Cypermethrin & 0.55 & 0.5 \\
\hline F5 K & Ravi, Horakere & ND & ND & ND \\
\hline F6 K & $\begin{array}{c}\text { C.M. Venkatappa, } \\
\text { Channapura }\end{array}$ & Malathion & 1.44 & 4 \\
\hline F7 K & Naranaswamy, Gangasandra & Imidacloprid & 0.001 & 1 \\
\hline F8 K & Venkateshappa, Kallur & ND & ND & ND \\
\hline F9 C & Bhairappa, Mungalahalli & Profenofos & 0.05 & 0.5 \\
\hline F10 C & $\begin{array}{c}\text { Manjunatha, } \\
\text { Yerramaranahalli }\end{array}$ & Chloropyriphos & 0.485 & ND \\
\hline F11 C & $\begin{array}{c}\text { Ramachandrappa, } \\
\text { Jonnalakunte }\end{array}$ & ND & ND & ND \\
\hline F12 C & $\begin{array}{c}\text { Munivenkatappa, } \\
\text { Kachakadatha }\end{array}$ & ND & ND & 4 \\
\hline F13 C & Nagaraj, Doddihally & Malathion & 1.5 & 0.01 \\
\hline F14 C & Suresh, Bommenahalli & Dieldrin & 0.002 & ND \\
\hline F15 C & Ayyappa, Angatta & ND & ND & \\
\hline
\end{tabular}

F: Farmer

K: Kolar C: Chikkaballapura

ND: Not detected

Table.4 Pesticide residue in mulberry leaf sample collected from farmers' field of Chikkaballapura and Kolar Districts

\begin{tabular}{|c|c|c|c|c|}
\hline $\begin{array}{c}\text { Sample } \\
\text { code }\end{array}$ & Name and village & Detected insecticide & $\begin{array}{c}\text { Level of } \\
\text { pesticide } \\
\text { residue (ppm) }\end{array}$ & $\begin{array}{c}\text { FAO/WHO } \\
\text { Recommended } \\
\text { MRL (ppm) }\end{array}$ \\
\hline F1 K & Bhairegowda, Mallandahally & Chlorantraniliprole & Traces & 2 \\
\hline F2 K & Vishwanath, Chikkakalahalli & Dimethoate & 0.068 & 2 \\
\hline F3 K & Gouramma, Mullahalli & ND & ND & ND \\
\hline F4 K & Anjinappa, Guttahalli & ND & ND & ND \\
\hline F5 K & Ravi, Horakere & ND & ND & ND \\
\hline F6 K & $\begin{array}{c}\text { C.M. Venkatappa, } \\
\text { Channapura }\end{array}$ & ND & Traces & 2 \\
\hline F7 K & Naranaswamy, Gangasandra & Chlorantraniliprole & ND & ND \\
\hline F8 K & Venkateshappa, Kallur & ND & ND & 2 \\
\hline F9 C & Bhairappa, Mungalahalli & ND & 0.05 & ND \\
\hline F10 C & $\begin{array}{c}\text { Manjunatha, } \\
\text { Yerramaranahalli }\end{array}$ & Chlorantraniliprole & ND & 2 \\
\hline F11 C & $\begin{array}{c}\text { Ramachandrappa, } \\
\text { Jonnalakunte }\end{array}$ & ND & 0.29 & ND \\
\hline F12 C & $\begin{array}{c}\text { Munivenkatappa, } \\
\text { Kachakadatha }\end{array}$ & Chlorantraniliprole & ND & 2 \\
\hline F13 C & Nagaraj, Doddihally & ND & 0.03 & ND \\
\hline F14 C & Suresh, Bommenahalli & Glycel & ND & ND \\
\hline F15 C & Ayyappa, Angatta & ND: Not & \\
\hline
\end{tabular}

F: Farmer $\quad$ K: Kolar C: Chikkaballapura $\quad$ ND: Not detected 
Analysis of fifteen soil samples collected from different sericulture farmers' fields in Kolar and Chikkaballapura district for insecticides residue. Showed that out of fifteen samples, nine samples had detectable level of pesticides residue and those were PD.DDE (2.68ppm), Metalaxyl (0.19ppm), Cypermethrin (0.55ppm), Malathion (1.44ppm), Imidacloprid (0.001ppm), Profenofos (0.05ppm), Chloropyriphos (0.485ppm), Malathion (1.5ppm) and Dieldrin (0.002ppm) in F1 K, F2 K, F4 K, F6 K, F7 K, F9 C, F10 C, F13 C and F14 C respectively. Out of these, only one sample (F4K) contained residue of Cypermethrin (0.55ppm) above MRL (0.5ppm) (Table 3). This might be due to accumulation of pesticides in soil from time to time. The results are in conformity with Fatema et al., (2013) and Charles (2009).

Results of analysis of fifteen mulberry leaf samples collected from different sericulture farmer fields in Kolar and Chikkaballapura district for insecticides residue. Showed that out of fifteen samples, six samples had detectable level of pesticides residue and those were Chlorantraniliprole (traces), Dimethoate (0.068ppm), Chlorantraniliprole (traces), Chlorantraniliprole (0.05ppm), Chlorantraniliprole (0.29ppm) and Glycel (0.03ppm) in F1 K, F2 K, F7 K, F10 C, F12 C and $\mathrm{F} 14 \mathrm{C}$ respectively.

Out of these, only one sample (F12 C) contained residue of Chlorantraniliprole (0.29ppm) above MRL (0.29ppm) (Table 4). This might be due to direct application of pesticide onto the plants, where by the leaves having a greater surface area absorbed high level of pesticides and resulted in residual toxicity. This is in conformity with Andrea et al., (2009). They reported that the residue of Chlorantraniliprole was effective upto 30days after spraying, at 22days after spraying the residual toxicity were above MRL.
Fifteen samples of soil and mulberry leaves were analysed for pesticide residue. Among them only nine samples had detectable level of pesticide residue in soil, out of this only one sample (F4K) contained residue of cypermethrin (0.55ppm) above MRL (0.01ppm). Similarly in mulberry leaves only one sample (F12C) contained residue of Chlorantraniliprole $(0.29 \mathrm{ppm})$ on par with (0.29ppm).

From the field survey in villages of Ramanagara, Chikkaballapur and Kolar Districts revealed that the maximum toxicity of pesticides was due to the drift effect (66 farmers) followed by direct effect (38 farmers). Majority farmers preferred Chlorantraniliprole followed by Flubendamide (25 farmers), to manage pest of intercrop grown in mulberry. And from fifteen samples of soil and mulberry leaves were analysed for pesticide residue. Among them only nine samples had detectable level of pesticide residue in soil, out of this only one sample $(\mathrm{F} 4 \mathrm{~K})$ contained residue of cypermethrin (0.55ppm) above MRL (0.01ppm). Similarly in mulberry leaves only one sample (F12C) contained residue of Chlorantraniliprole (0.29ppm).

\section{References}

Andrea, B., Rison, J.L. and Wiles, J.A., 2009, Chlorantraniliprole, a new diamide insecticide for control of codling moth (cydiapomonella), colorado potato beetle (Leptinotarsa decemlineata) and european grapevine moth (Lobesia botrana). Dvrs.bf.uni-lj.si/spvr, pp: 3945.

Avramova, K., Grekov, D., Ivanova, R. and Hristev, H., 2012, Some typical symptoms of mulberry silkworm poisoning with the Neonicotinoide Insecticides (Confidor and Actara). $J$. Animal Science, 55(2)107-108. 
Chandrashekharan, K., Nataraju, B., Balavankatasubbaiah. Sharma, S.D., Selvakumar, T. and Sudhakara RAO, P., 2007, Residual toxicity problems in sericulture. Indian silk, pp: 7-9.

Charles, K. and Rubhera, R.M., 2009, Distribution of pesticide residues in soil due to point source pollution at old Korogwe, Tanzania. Int. J. Biol. Chem. Sci, 3(3): 422-430.

Fatema,M., Rahman,M.M., Kabir,K. H., Mahmudunnabi, M. and Akter, M. A., 2013, Residues of insecticide in farm and market samples of Eggplant in Bangladesh. Journal of Entomology and Zoology Studies, 1(6): 147-150.

Jyothi, J., Ashoka, M., Bheemanna, A.,
Nagangouda, A.G., Sreenivas and Jayashree, M., 2013, Waiting period for insecticides and a botanical used in control of Mulberry Thrips. Ann. Pl. Protec. Sci., 21(1): 42-45.

Kumutha, P., Padmalatha, C. and Ranjit Singh, A. J. A., 2013, Effect of pesticides on the reproductive performance and longevity of Bombyxmori L. Int. J. Curr. Microbiol. App. Sci., 2(9):74-78.

Roxelle, F. M., Thais, S. B. and Shunsuke, M., 2013, Evaluation of the toxic effect of Insecticide Chlorantraniliprole on the silkworm, Bombyx mori L. J. Animal Sci., 3(4): 343-353.

\section{How to cite this article:}

Sunil Kumar, T., Ramakrishna Naika, G. Ashwini and Anitha, K. 2017. Field Survey and Estimation of Residual Toxicity of Insecticides Used in Mulberry Growing Area of Karnataka, India. Int.J.Curr.Microbiol.App.Sci. 6(12): 4170-4175.

doi: https://doi.org/10.20546/ijcmas.2017.612.479 